\title{
SUPPORTING INFOMAYION
}

\section{Metal Ion Size-dependent Effects on Lipid}

\section{Transmembrane Flip-Flop}

Yong-Hao Ma,,$^{\dagger}$ Bolin Li, ${ }^{\ddagger}$ Jingjing Yang, ${ }^{\S}$ Xiaofeng Han, ${ }^{\dagger}$ Zhan Chen, ${ }^{*,+}$ and Xiaolin Lu ${ }^{*},+$

${ }^{\dagger}$ State Key Laboratory of Bioelectronics, School of Biological Science and Medical Engineering, Southeast University, Nanjing 210096, China

\$Department of Chemistry, University of Michigan, Ann Arbor, Michigan 48109, United States

$\S^{\S}$ Department of Biomedical Engineering, College of Engineering and Applied Sciences, Nanjing University, Nanjing 210093, China 
SFG for a charged water interface. Concerning the contributions from the second-order surface nonlinear susceptibility $\chi_{S}^{(2)}$ and the third-order bulk nonlinear susceptibility $\chi_{B}^{(3)}$ to the collected $\mathrm{OH}$ stretching vibrational signals $\left(\chi_{e f f}^{(2)}\right)$ in the presence of the interfacial potential $\Phi(0)$, eq 2 can be expanded to

$$
I_{S F G} \propto\left|\chi_{e f f}^{(2)}\right|^{2}=\left|\chi_{N R}^{(2)}+\chi_{S}^{(2)}+\frac{\kappa}{\sqrt{\kappa^{2}+\Delta k_{Z}^{2}}} e^{i \arctan \left(\Delta k_{z} / \kappa\right)} \chi_{B}^{(3)} \Phi(0)\right|^{2}
$$

Here, $\kappa$ is the inverse of the Debye length and $\Delta k_{z}$ describes the phase mismatch of the reflected SFG. At the high electrolyte concentration like $100 \mathrm{mM}$, we have $\Delta k_{z} / \kappa \ll 1$, therefore,

$$
I_{S F G} \propto\left|\chi_{e f f}^{(2)}\right|^{2}=\left|\chi_{N R}^{(2)}+\chi_{S}^{(2)}+\chi_{B}^{(3)} \Phi(0)\right|^{2}
$$

For a $2: 1$ electrolyte like $\mathrm{CaCl}_{2} / \mathrm{SrCl}_{2} / \mathrm{BaCl}_{2}$, the interfacial potential $\Phi(0)$ can be calculated using the Grahame equation based on the Gouy-Chapman model,

$$
\Phi(0)=\frac{R T}{F} \ln y
$$

with

$$
2 \mathrm{y}^{3}-\left(3+\frac{\sigma^{2}}{2 \varepsilon_{0} \varepsilon_{r} R T C}\right) \mathrm{y}^{2}+1=0
$$

where $\sigma$ is the surface charge density of the DPPC bilayer and $C$ is the ionic concentration.

For the all three divalent ions $\left(\mathrm{Ba}^{2+}, \mathrm{Sr}^{2+}\right.$, and $\left.\mathrm{Ca}^{2+}\right)$ at the same concentration of $100 \mathrm{mM}$, the interfacial potentials $\Phi(0)$ were same. Therefore, the $\chi_{B}^{(3)} \Phi(0)$ contributions to the measured $\chi_{e f f}^{(2)}$, for the three ions, were the same based on the independent $\chi_{B}^{(3)}$ for the interfacial system 
chosen. As a result, the differences of the collected water $\mathrm{OH}$ stretching signals $\left(\chi_{e f f}^{(2)}\right)$ at the certain surface pressure were mainly due to the $\chi_{S}^{(2)}$ changes. For a certain cation (for example $\mathrm{Ca}^{2+}$ ) under different surface pressures, both $\chi_{B}^{(3)} \Phi(0)$ and $\chi_{S}^{(2)}$ would be different. Therefore, in the main text, $\chi_{e f f}^{(2)}$ for the water $\mathrm{OH}$ stretching signals (including both $\chi_{B}^{(3)} \Phi(0)$ and $\chi_{S}^{(2)}$ ) was discussed, which would not affect our final conclusion. 


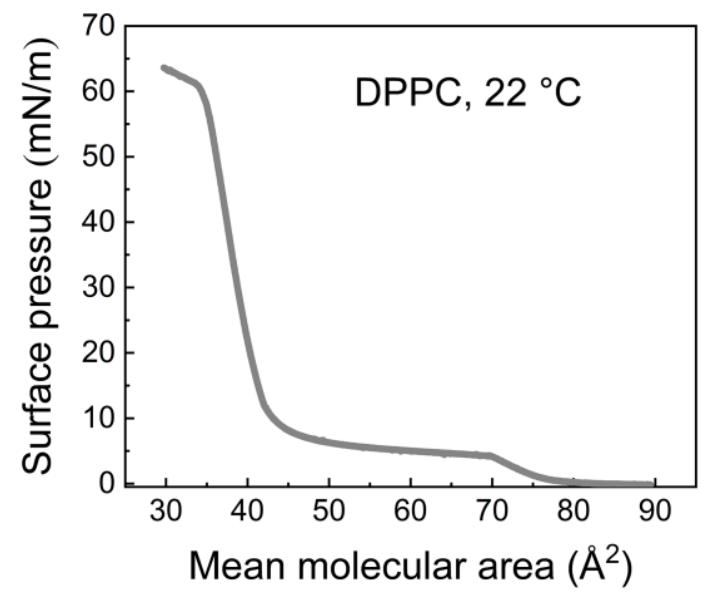

Figure S1. Pressure-area $(\pi-\mathrm{A})$ isotherm of DPPC at $22{ }^{\circ} \mathrm{C}$.

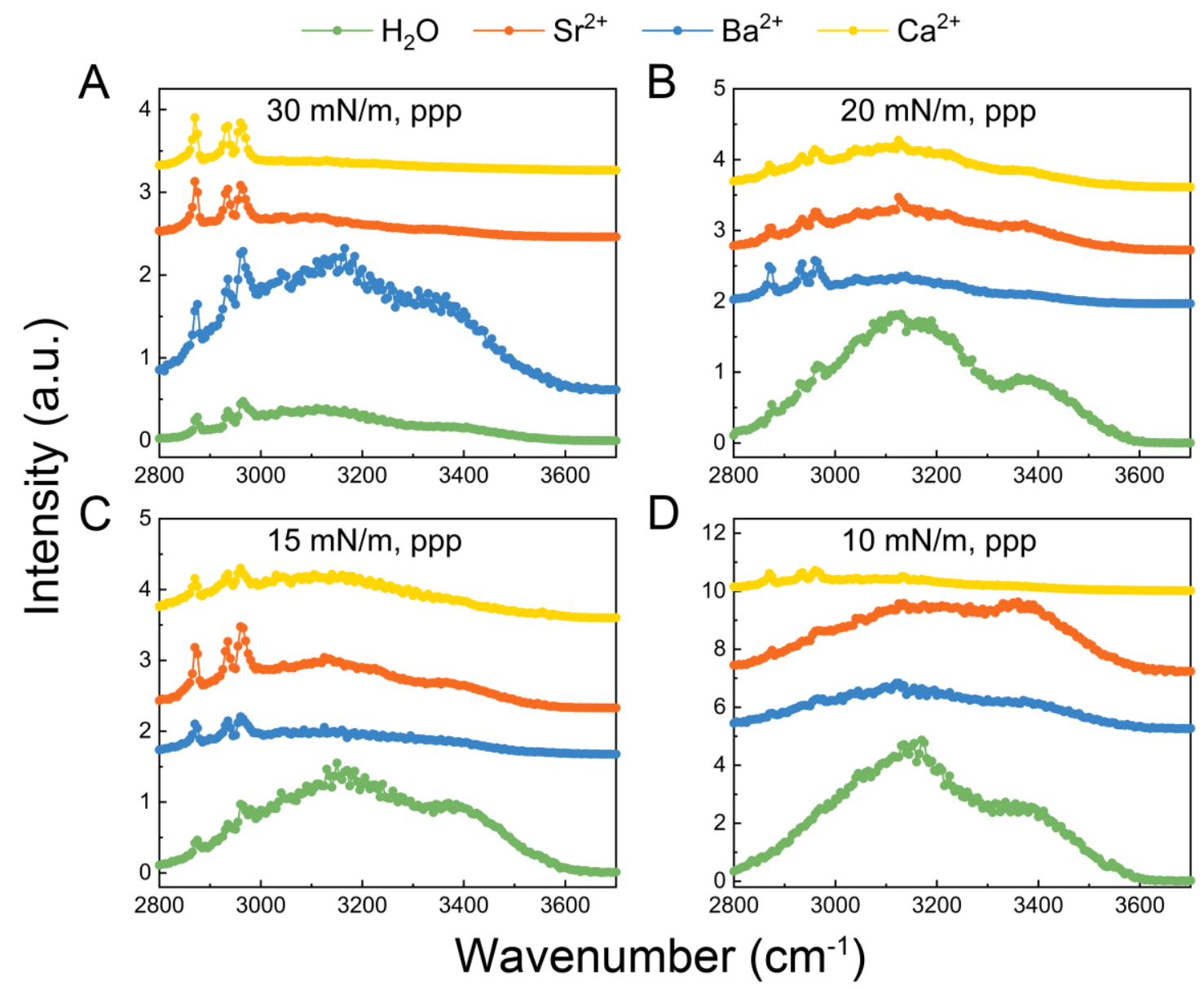


Figure S2. Static SFG spectra for the dDPPC-DPPC bilayers in contact with the ionic solutions $\left(100 \mathrm{mM} \mathrm{Ca}^{2+,} 100 \mathrm{mM} \mathrm{Sr}^{2+}, 100 \mathrm{mM} \mathrm{Ba}^{2+}\right)$ and water at different surface pressures $(30,20,15$, and $10 \mathrm{mN} / \mathrm{m})$. The spectra were collected after flip-flop process.

Table S1. Integrated Water OH Vibrational Intensities ${ }^{a}$

\begin{tabular}{|c|c|c|c|c|c|c|c|c|}
\hline \multirow{2}{*}{$\begin{array}{c}\pi \\
(\mathrm{mN} / \\
\mathrm{m})\end{array}$} & \multicolumn{4}{|c|}{ Area $(\mathrm{OH}, \mathrm{ssp})$} & \multicolumn{4}{|c|}{ Area $(\mathrm{OH}, \mathrm{ppp})$} \\
\hline & $\left(\mathrm{H}_{2} \mathrm{O}\right)$ & $\mathrm{Ba}^{2+}$ & $\mathrm{Sr}^{2+}$ & $\mathrm{Ca}^{2+}$ & $\left(\mathrm{H}_{2} \mathrm{O}\right)$ & $\mathrm{Ba}^{2+}$ & $\mathrm{Sr}^{2+}$ & $\mathrm{Ca}^{2+}$ \\
\hline 30 & $\begin{array}{c}23.3 \pm \\
3.5\end{array}$ & $\begin{array}{c}129.5 \pm \\
79.9\end{array}$ & $\begin{array}{c}15.8 \pm \\
10.0\end{array}$ & $\begin{array}{c}10.7 \pm \\
2.6\end{array}$ & $\begin{array}{c}124.1 \pm \\
48.9\end{array}$ & $\begin{array}{c}584.9 \pm \\
206.8\end{array}$ & $\begin{array}{c}68.2 \pm \\
41.2\end{array}$ & $\begin{array}{c}35.6 \pm \\
7.5\end{array}$ \\
\hline 20 & $\begin{array}{c}106.9 \pm \\
64.6\end{array}$ & $\begin{array}{c}23.7 \pm \\
2.4\end{array}$ & $\begin{array}{c}50.2 \pm \\
5.2\end{array}$ & $\begin{array}{c}52.5 \pm \\
5.0\end{array}$ & $\begin{array}{c}607.4 \pm \\
312.5\end{array}$ & $\begin{array}{c}111.2 \pm \\
29.9\end{array}$ & $\begin{array}{c}207.8 \pm \\
76.3\end{array}$ & $\begin{array}{c}181.1 \pm \\
48.3\end{array}$ \\
\hline 15 & $\begin{array}{c}80.6 \pm \\
0.5\end{array}$ & $\begin{array}{c}21.8 \pm \\
4.8\end{array}$ & $\begin{array}{c}43.4 \pm \\
11.7\end{array}$ & $\begin{array}{c}58.8 \pm \\
18.3\end{array}$ & $\begin{array}{c}538.4 \pm \\
35.3\end{array}$ & $\begin{array}{c}118.9 \pm \\
27.3\end{array}$ & $\begin{array}{c}230.6 \pm \\
76.6\end{array}$ & $\begin{array}{c}205.6 \pm \\
71.5\end{array}$ \\
\hline 10 & $\begin{array}{c}246.7 \pm \\
39.5\end{array}$ & $\begin{array}{c}108.7 \pm \\
40.9\end{array}$ & $\begin{array}{c}201.2 \pm \\
19.7\end{array}$ & $\begin{array}{c}26.8 \pm \\
8.0\end{array}$ & $\begin{array}{c}1580.4 \pm \\
493.0\end{array}$ & $\begin{array}{c}538.9 \pm \\
205.6\end{array}$ & $\begin{array}{c}1051.9 \pm \\
350.0\end{array}$ & $\begin{array}{c}126.2 \pm \\
71.0\end{array}$ \\
\hline $\begin{array}{l}{ }^{a} \text { Integ } \\
\text { dDPP } \\
\text { mM }\end{array}$ & 1 & $\mathrm{H}$ & nnol & .8 & & & $700 \mathrm{~cm}$ & $\begin{array}{l}\text { for the } \\
r^{2+}, 100 \\
\text { he water }\end{array}$ \\
\hline
\end{tabular}




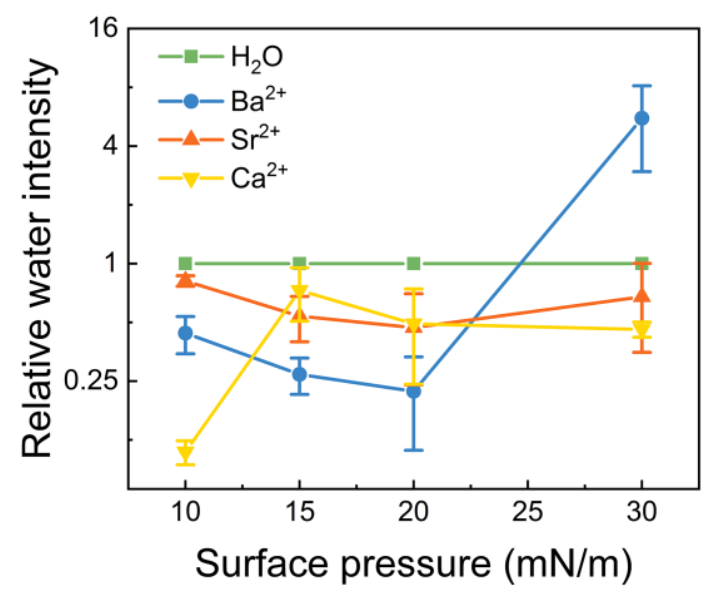

Figure S3. Relative water intensities (ssp) for the dDPPC-DPPC bilayers for the $\mathrm{Ba}^{2+}, \mathrm{Sr}^{2+}$, and $\mathrm{Ca}^{2+}$ ions versus the surface pressure.

Ion effects on the flip-flop process of the PS-containing bilayers. The negatively charged lipids (DPPS) were added to the proximal leaflet of a bilayer at the molar ratio of 1:9 with the dDPPC lipids. The distal leaflet of the bilayer was constructed using the dDPPC lipids. The formed DPPS1dDPPC9-dDPPC bilayer can generate the SFG signals at $2875 \mathrm{~cm}^{-1}$, which can represent the flip-flop of the DPPS lipids. When the subphase was water, compared with the pure dDPPC-DPPC bilayer at the same surface pressure of $30 \mathrm{mN} / \mathrm{m}$ (Figure 2A), the flip-flop process of the DPPS1dDPPC9-dDPPC bilayer was accelerated obviously upon the addition of the negatively charged DPPS (Figure S4), as a result of the DPPS-induced defects for the DPPS1dDPPC9-dDPPC bilayer. Moreover, for the DPPS1dDPPC9-dDPPC bilayers, the $\mathrm{Ca}^{2+}$ ions in the subphase can accelerate the flip-flop process compared with the case when the subphase was water, due to the electrostatic attraction between the negatively charged DPPS lipids and the positively charged $\mathrm{Ca}^{2+}$ ions. 


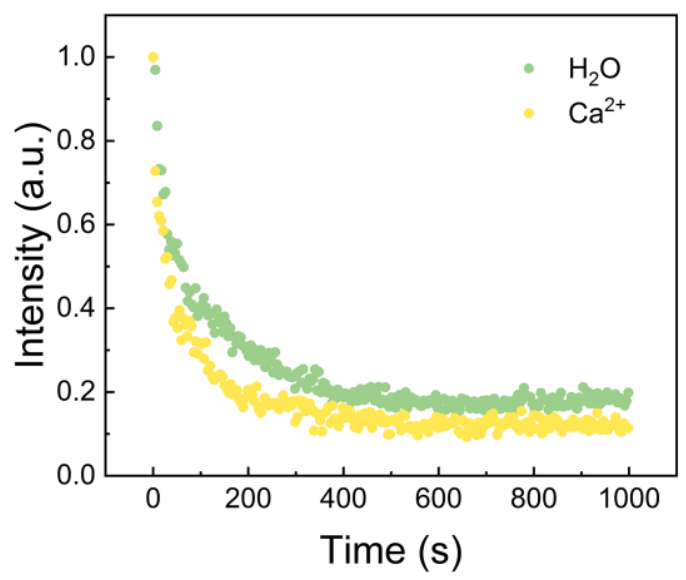

Figure S4. Decay curves of the time-dependent SFG signals at $2875 \mathrm{~cm}^{-1}$ (methyl stretching vibrational mode) for the DPPS1dDPPC9-dDPPC bilayers in contact with different subphases (water and $100 \mathrm{mM} \mathrm{Ca}{ }^{2+}$ ) at the surface pressure of $30 \mathrm{mN} / \mathrm{m}$. 